\title{
A FORMAÇÃO PARA O ENSINO DE MATEMÁTICA DE PROFESSORAS INICIANTES
}

\author{
Klinger Teodoro Ciríaco, Gislaine Aparecida Puton Zortêa \\ Universidade Federal de Mato Grosso do Sul - UFMS, Curso de Pedagogia, Naviraí, MS. E-mail: klingerufms@hotmail.com
}

\section{RESUMO}

O presente artigo tem como fundamento apresentar a formação para o ensino dos conteúdos matemáticos de professoras iniciantes que atuam na rede pública do munícipio de Naviraí, interior de Mato Grosso do Sul - MS. Para tanto, foram analisadas informações da ementa da disciplina que aborda a Matemática na grade curricular da formação inicial em Pedagogia de uma Instituição de Ensino Superior (IES), da qual as docentes são egressas. O eixo metodológico adotado se inscreve no campo da pesquisa qualitativa de caráter descritivo-analítico e os dados foram analisados a luz de um referencial teórico que contemplou questões ligadas ao início da docência e formação inicial para a docência. Com a realização da pesquisa, detectamos problemas em relação ao conhecimento específico dos conteúdos matemáticos no decorrer do curso, tendo em vista que muitas vezes as ementas das disciplinas trazem descrições de uma formação centrada em procedimentos metodológicos e não se atentam para questões conceituais necessárias à prática pedagógica, o que pode acarretar em desafios na fase iniciação à docência.

Palavras-chave: Formação Matemática; Curso De Pedagogia; Professoras Iniciantes.

\section{TRAINING FOR TEACHERS OF MATHEMATICS EDUCATION BEGINNERS}

\begin{abstract}
This article is based provide training for the teaching of mathematical content of beginning teachers who work in the municipality public network Naviraí, inside of Mato Grosso do Sul - MS. To that end, it analyzed the information menu of the discipline that deals with mathematics in the curriculum of initial training in pedagogy of a Higher Education Institution ( $\mathrm{HEI}$ ), which the teachers are graduates. The methodology adopted axis falls within the field of qualitative research of descriptive and analytical and the data were analyzed in light of a theoretical framework which included issues related to early teaching and initial training for the teaching. With the completion of the research, we identify problems in relation to specific knowledge of the mathematical content during the course, considering that often the menus of the disciplines bring descriptions of a training centered on methodological procedures and do not pay attention to conceptual issues needed to practice pedagogical, which can lead to challenges in the initiation phase to teaching.
\end{abstract}

Keywords: Mathematics Education; Faculty of Education; Teachers beginners.

\section{INTRODUÇÃO}

A necessidade de conhecer de forma abrangente a temática abordada nesse artigo emergiu em decorrência de nossa participação no Grupo de Estudos e Pesquisas sobre Início da Docência e Ensino de Matemática GEPIDEM/UFMS/CNPq - em ações voltadas para estudos e reflexões sobre os problemas da formação inicial para o ensino e aprendizagem dos conceitos escolares, como também questões ligadas ao professor iniciante em diferentes níveis de atuação com base no desenvolvimento de uma pesquisa institucional cadastrada na PróReitoria de Pesquisa e Pós-Graduação da Universidade Federal de Mato Grosso do Sul PROPP/UFMS.
A participação no referido grupo, fez-nos observar que a literatura especializada na área, demonstra que vários dos cursos de formação inicial $^{1}$ trabalham apenas embasamentos metodológicos e não se atentam para o conhecimento específico da Matemática.

Nessa perspectiva, tendo em vista que quando formados nos deparamos com os dilemas no começo da carreira e vivenciamos, com isso, o desafio de ensinar aquilo que nem sempre aprendemos, emergiram algumas questões que foram primordiais para a realização do estudo, a saber:

\footnotetext{
${ }^{1}$ Especificamente os cursos de Pedagogia (CURI, 2004).
} 
- Qual a formação para o ensino de Matemática obtida no curso de licenciatura em Pedagogia?

- $\quad$ Que saberes professores novatos mobilizam no processo do aprender a ensinar os conceitos matemáticos?

- Que abordagens metodológicas são adotadas para o ensino desses conteúdos?

Nesse artigo, trouxemos para o diálogo os dados sobre a análise da ementa da disciplina de fundamentos do ensino dos conteúdos matemáticos presente na formação inicial das professoras colaboradoras da pesquisa.

\section{O início da carreira e a formação matemática no curso de Pedagogia}

São muitos os problemas que o docente encontra na fase de entrada na carreira e, de acordo com Veenman (1984), o mais completo refere-se ao "choque com a realidade", sentimento decorrente das expectativas iniciais em relação à carreira e a realidade vivenciada nas escolas. Tal sensação leva o professor a repensar tudo o que foi estudado e fazer uma sistematização disso com a prática.

Deste modo, podemos entender que o "[...] início da carreira docente está intimamente ligado ao período que antecede esta atuação, ou seja, a formação profissional" (ROCHA, 2004, p. 04) e, no caso da presente pesquisa, suas experiências com a Matemática no decorrer de sua formação nos cursos de Pedagogia.

Souza (2009) considera que é no começo da carreira que o professor se vê a mercê da sorte, sem ter com quem compartilhar suas dificuldades. Com isso, a autora afirma ainda que por não ter experiência profissional, "[...] 0 professor acaba apoiando sua prática em ações que vivenciou na época de estudante, reproduzindo a prática de seus antigos professores [...]" (SOUZA, 2009, p. 37).

Assim, ainda descrevendo características das dificuldades deste momento, a autora enfatiza que "[...] é importante ressaltar que se são os piores anos, também constituem um momento profícuo para mudanças e desenvolvimento profissional [...]" (SOUZA, 2009, p. 38) podendo instigar o docente a ter uma maior consciência de seus métodos de ensino levando-o a investigar por meio de suas vivências, inseguranças e experiências seus acertos e erros, para saber como atuar, adotando esse momento como fundamental para a constituição de uma identidade profissional, pois se por um lado a uma complexidade inicial que distancia a realidade vivida em sala de aula das teorias estudadas, por outro lado há entusiasmo em conhecer a melhor forma de lidar com os conteúdos programados que por vezes são dados como abstrusos, assim o "[...] turbilhão de sentimentos como angústia, insegurança, vivenciados pelo professor, dialeticamente [...]" passa a ser "[...] combustível para que este possa se reafirmar na profissão" (SOUZA, 2009, p. 39).

Se em um primeiro momento o início de carreira é difícil, notaremos, então, que muitos acadêmicos de Pedagogia não entendem a complexidade do processo de ensino e aprendizagem da Matemática escolar no curso de formação inicial por se tratar, muitas vezes, de "[...] uma formação centrada em processos metodológicos, desconsiderando os fundamentos da matemática" (NACARATO; MENGALI; PASSOS, 2009, p. 17).

A desatenção por parte do curso faz com que $\mathrm{o}$ futuro professor não dê a devida importância ao conhecimento matemático, o que acaba por reforçar "[...] uma concepção dominante de que o professor polivalente não precisa 'saber Matemática' e que basta saber como ensiná-la" (CURI, 2004, p. 77).

No seguimento do atrás referido, por terem essas convicções, os professores iniciantes pelo perfil de formação deixam de lado conhecimentos de cunho teóricos no começo da carreira e quando ensinam, acabam por adotar práticas mecanizadas baseadas em procedimentos de memorização de técnicas, além da forte dependência do livro didático, conforme destaca Pavanello (2002).

O despreparo do curso de Pedagogia torna muitas vezes os acadêmicos analfabetos matematicamente, por não abordar, no percurso formativo, os conceitos fundamentais da Matemática e suas propriedades. $\mathrm{O}$ resultado do perfil de formação contribui para a construção de uma prática pedagógica "[...] centrada em cálculos e procedimentos" (NACARATO; MENGALI; PASSOS, 2009, p. 32), que não leva em consideração recomendações tanto de documentos oficiais para o ensino dos conteúdos matemáticos quanto das tendências metodológicas atuais que se baseiam na problematização e resolução de problemas como eixo central do trabalho pedagógico nos anos iniciais do Ensino Fundamental (BRASIL, 1997). 
Pesquisas $^{2}$ e a própria experiência no contexto da formação inicial de professores demonstram que a Matemática é apresentada no curso de Pedagogia de maneira fragmentada, de forma que não contribui para a formação específica dos acadêmicos em relação aos conteúdos matemáticos que precisam ser iniciados nos primeiros anos de escolarização. Nacarato et al (2004) argumentam que os alunos do curso de Pedagogia não costumam utilizar de estratégias de forma exploratória para resolver problemas ou explicar a maneira de pensar/realizar atividade referente aos conteúdos programados.

Gomes (2006, p. 53), em estudos sobre os obstáculos epistemológicos em relação à Matemática, aponta que:

É preciso alterar a relação que os estudantes, futuros professores, estabelecem com a matemática. Se o ensino deve voltar-se para a construção de conhecimento de modo que as crianças sejam encorajadas a solucionar diferentes situações-problemas, é antes necessário que se dê oportunidade aos futuros professores de fazerem 0 mesmo, pois como poderão encorajar e estimular seus alunos quem nunca teve esta oportunidade em toda sua trajetória escolar?

Para a autora "[...] a mudança não deve ocorrer apenas em torno do currículo, de materiais de apoio, mas, sobretudo, sobre o modo de entender e conceber a matemática [...]" no decorrer da formação inicial.

Vasconcellos (2009), em sua tese de doutorado, ao investigar os saberes mobilizados no início da carreira em relação aos conteúdos matemáticos, constatou que os professores iniciantes quando indagados sobre a disciplina de Matemática presente no curso de Pedagogia revelaram sentimentos negativos de aflição e descontentamento.

Para Gomes (2002, p. 364)

[...] a aprendizagem matemática ainda se constitui em um grande problema, tanto para crianças quanto para os professores que estão sendo formados nos cursos de Pedagogia. Isso justifica, muitas vezes, que a própria opção pelo curso seja determinada pela inexistência de matemática em sua grade curricular.

Contudo, no decorrer do tempo, a disciplina de Fundamentos e Metodologias do Ensino de Matemática, apresenta-se durante o processo formativo e os futuros professores passam a lidar com medos e conflitos decorrentes, muitas vezes, de experiências negativas em relação a essa área do conhecimento.

Logo, temos um grande desafio no curso de Pedagogia, o de desmistificar mitos e equívocos sobre o que seja aprender e ensinar conteúdos matemáticos nos primeiros anos de escolarização, uma vez que o profissional terá de introduzir os conceitos com as crianças.

Assim, é preciso compreendermos "[...] a necessidade de a formação inicial oportunizar aos acadêmicos conhecimentos e aprendizagens que beneficiem a construção dos aspectos epistemológicos da disciplina de matemática" (BEDNARCHUK, 2012, p. 23).

Como são raramente demonstrados aspectos lúdicos e prazerosos da aprendizagem matemática nos cursos de licenciatura na área, alguns professores ainda têm um sentimento de aversão à matéria (CURI, 2004) por não terem domínio necessário para o ensino dos referidos conteúdos. Curi (2005), em sua pesquisa de doutorado, analisou 36 instituições e constatou:

[...] a pouca presença de conteúdos matemáticos e de suas didáticas nos currículos dos cursos de Pedagogia. Cabe destacar que a organização da disciplina de Metodologia do Ensino de Matemática, em algumas instituições, era unificada à outra referente aos conteúdos matemáticos. $\mathrm{Na}$ maioria, porém, a disciplina tinha caráter mais metodológico, com predominância de temas de caráter mais geral do ensino de Matemática em detrimento de discussões

${ }^{2}$ Curi (2004); Nacarato, Mengali e Passos (2009); Vasconcellos (2009). 
metodológicas sobre temas matemáticos previstos para serem desenvolvidos nos anos iniciais do ensino fundamental (p. 8).

Os dados da tese da autora apontaram que além de ter uma carga horária que varia entre 36 e 120 horas, os cursos trazem nas ementas das disciplinas referenciais sobre o trabalho pedagógico com metodologias de ensino centradas na utilização de jogos e brincadeiras sem uma relação direta com as propriedades matemáticas dos conceitos, ou seja, são apresentados, aos professores em formação inicial, textos teóricos que discutem bases da organização do ensino dissociadas do conhecimento do conteúdo. Essa realidade demonstra o empobrecimento da formação para o ensino de Matemática na Pedagogia.

Bednarchuk (2012), em concordância com Curi (2004), evidencia que o curso de Pedagogia sofre "duras" críticas a respeito da formação de professores que ensinam matemática:

\begin{tabular}{|c|}
\hline $\begin{array}{l}\text { Várias são as crít } \\
\text { destinadas aos cursos } \\
\text { licenciatura em Pedago } \\
\text { pois além de possuírem } \\
\text { suas grades curricula } \\
\text { carga horária mínima par } \\
\text { disciplinas que tratam } \\
\text { formação matemática, } \\
\text { ementas das mesmas } \\
\text { apresentam esvaziadas } \\
\text { aspectos conceituais } \\
\text { conteúdos matemáticos }\end{array}$ \\
\hline
\end{tabular}

Seguindo essa mesma linha de raciocínio, Ciríaco e Teixeira (2014, p. 159) evidenciam que:

[...] é preciso que os cursos de Licenciatura em Pedagogia trabalhem referenciais teórico-metodológicos dos conteúdos básicos de Matemática e de seu ensino, de maneira que possibilite aos futuros professores refletirem sobre o ensino dos conteúdos dessa área, tanto na Educação Infantil quanto nos Anos Iniciais do Ensino Fundamental.

Ao analisar o atrás exposto, acreditamos que por ter esse perfil formativo, os professores iniciantes, acabam por carregar ao longo da prática pedagógica resquícios desse déficit e isso pode contribuir para os problemas da aprendizagem de conceitos nos anos iniciais do Ensino Fundamental. Além disso, a formação matemática oportunizada no contexto do curso contribui para o reforço de práticas mecanizadas baseadas em procedimentos de memorização de técnicas.

A partir da referida constatação, de que a formação de professores para o ensino de Matemática apresenta-se fragmentada e distante das atuais tendências curriculares da escola, acreditamos que possa existir um bloqueio para a aprendizagem da docência na área, uma vez que as experiências das futuras professoras parecem estar atreladas às crenças e concepções negativas que obtiveram ao longo da formação escolar.

O fato pode comprometer, de forma significativa, o período de início da docência e resultar em dificuldades epistemológicas em relação aos conteúdos que terão de ensinar, haja vista que as professoras já estão condicionadas ao sentimento de incapacidade sobre o ensino de Matemática.

Sobre essa questão, Nono e Mizukami (2006, p. 340) afirmam que:

[...] a formação inicial do
professor das primeiras séries
tem investido pouco no
ensino de matemática, o que
reflete nos baixos índices de
desempenho dos alunos das
séries iniciais do ensino
fundamental nessa área em
avaliações externas de nível
nacional.

Nono e Mizukami (2006, p. 341) advertem ainda "[...] que nenhum professor consegue criar, planejar, realizar, gerir e avalizar situações didáticas eficazes para aprendizagem sem o domínio de conteúdos específicos das áreas de conhecimento".

Para que esse domínio seja possível é necessária uma apropriação da matéria por parte de quem ensina, ou seja, o professor precisa ter domínio dos procedimentos que regem a área de sua atuação. Com isso, indagamos: como ensinar algo que nem sempre se aprendeu e quais os desafios presentes na organização do trabalho pedagógico com a Matemática nos primeiros anos da docência?

Em suma, é recomendado, de acordo com Nono e Mizukami (2006, p. 347), que os 
professores novatos "[...] ampliem sua própria competência na resolução de situações-problema [...]" gerando questões problemas e procurando a forma mais adequada para a resolução, favorecendo o entendimento do aluno ao que diz respeito das matérias propostas.

Por fim, concluímos que ao longo da formação é necessária a construção de esquemas que proporcionem reflexão sobre os conteúdos programados e os métodos de resolução, fazendo com que o futuro professor experiencie a prática do aprender e do ensinar.

\section{Procedimentos metodológicos}

O estudo em questão se inscreve no campo da pesquisa qualitativa em educação com um caráter descritivo-analítico por se tratar de ações que envolveram a participação da pesquisadora direta no ambiente investigado (LÜDKE; ANDRÉ, 1986).

Os dados foram coletados no contexto de uma pesquisa institucional cadastrada na PróReitoria de Pesquisa e Pós-Graduação - PROPP da Universidade Federal de Mato Grosso do Sul/UFMS, câmpus de Naviraí intitulada "Trajetórias formativas de professores iniciantes: o percurso de desenvolvimento profissional e aprendizagem colaborativa da docência em Matemática", em andamento desde agosto de 2013, com o objetivo de compreender processos de aprendizagem da docência em um grupo de professoras iniciantes que atuam na rede municipal de educação de Naviraí/MS.

Assim, a elaboração do trabalho envolveu, além de uma entrevista semiestruturada com as docentes, a análise documental da ementa da disciplina de Fundamentos e Metodologias do Ensino de Matemática presente nos cursos de licenciatura dos quais as professoras participantes são egressas e que será apresentada nesse artigo com vistas à compreensão do perfil do profissional que ensina essa área do conhecimento.

De acordo com Silva et. al. (2009) a análise documental possibilita ao pesquisador perceber elementos que podem revelar o modo de ser, viver e compreender um fato social pelo homem, uma vez que as fontes de registro escrito também expressam concepções.

Lüdke e André (1986) consideram que “[...] a análise documental pode se constituir numa técnica valiosa de abordagem de dados qualitativos seja complementando as informações obtidas por outras técnicas, seja desvelando aspectos novos de um tema ou problema".

Ao final, os dados da ementa foram transcritos e analisados com base na elaboração de uma categoria que visou atender as expectativas iniciais do estudo: descrever a formação matemática presente no curso de Pedagogia.

\section{Algumas características da formação para o ensino de Matemática}

O objetivo desse tópico é análise as características da formação matemática no curso de Pedagogia em que as professoras colaboradoras da pesquisa se formaram. Para isso, realizamos um levantamento junto a Instituição de Ensino Superior (IES) particular ${ }^{3}$ em que as docentes são egressas para ter uma maior compreensão de como os conteúdos matemáticos estão/foram dispostos na licenciatura.

Assim, elaboramos um quadro com características muito específicas desse perfil formativo, como pode-se observar abaixo:

Quadro 01. Características da formação matemática presente no curso de Pedagogia.

\begin{tabular}{|c|c|c|}
\hline DISCIPLINA & CH & EMENTA \\
\hline $\begin{array}{l}\text { Fundamentos e } \\
\text { Metodologia do } \\
\text { Ensino } \\
\text { Matemática }\end{array}$ & $\begin{array}{l}80 \\
\text { horas }\end{array}$ & $\begin{array}{l}\text { Matemática no ensino } \\
\text { dos anos iniciais do } \\
\text { ensino fundamental: } \\
\text { importância } \\
\text { significado, alternativas } \\
\text { metodológicas, seleção e } \\
\text { estruturação dos } \\
\text { conteúdos, Geometria } \\
\text { intuitiva, números } \\
\text { naturais, o ensino de } \\
\text { problemas, materiais e } \\
\text { procedimentos didáticos. } \\
\text { Planejamento de ensino } \\
\text { da matemática. Analise e } \\
\text { uso dos livros didáticos }\end{array}$ \\
\hline
\end{tabular}

FONTE: Ementa da disciplina de Matemática da IES particular, 2013.

Observando o quadro 01, que descreve aspectos da abordagem matemática no curso de Licenciatura Plena em Pedagogia, podemos ressaltar que o ensino parece, pela escrita do texto, estar mais focado em aspectos metodológicos e, com isso, deixa de lado o ensino

\footnotetext{
3 As professoras iniciantes são egressas do mesmo curso de Pedagogia e, portanto, tiveram a mesma formação.
} 
específico da Matemática. Essa afirmativa é possível porque a ementa não faz menção às áreas específicas do conhecimento matemático como, por exemplo, números e sistema de numeração, grandezas e medidas, estatística, probabilidade, entre outros.

Ainda nessa análise, foi constatado que as leituras sugeridas pela bibliografia da disciplina referem-se à metodologia. São indicados os seguintes autores: Kamii (1984) para abordagem da construção do conceito de número; Dante (2000) ao destacar pontos da resolução de problemas; Cerquetti-Aberkane e Berdonneau (2001), Panizza (2006) questões que abordam os princípios dos conteúdos na Educação Infantil, muito embora essa área de atuação do professor não seja mencionada na ementa; Smole (2003) e as relações matemáticas e inteligências múltiplas; Nacarato e Lopes (2005) escritas e leituras em matemática, entre outros textos que descrevem abordagens metodológicas de ensino.

Nesse contexto, os professores iniciantes acabam levando para o início de carreira lacunas formativas decorrentes do pouco tempo e da falta de contato com o conteúdo específico destinados à disciplina nos cursos de formação de professores, conforme observamos.

Reconhecemos a importância do referencial mencionado, contudo, tal disciplina deve levar em consideração a defasagem do professor enquanto aluno e abordar os conteúdos em si, oferecendo-lhe respaldo maior sobre "o que" ensinar, ou seja, é preciso um movimento que torne o conhecimento "de" Matemática mais presente na formação inicial.

Para Curi e Pires (2008, p. 162) "[...] as disciplinas relativas à matemática e seu ensino que constam das grades curriculares dos cursos de pedagogia têm uma carga horária bastante reduzida". Em concordância com as autoras, defendemos o pressuposto de que é preciso a criação de disciplinas voltadas para essa área obedecendo às características de cada segmento de ensino (Educação Infantil e anos iniciais do Ensino Fundamental).

A ementa traz a discussão apenas sobre a Matemática dos anos iniciais, bem como a importância dela para os alunos, entretanto, não vimos nenhuma menção a Educação Infantil, momento esse que também é possível trabalhar conteúdos matemáticos com as crianças a partir de brincadeiras, tornando $o$ ato de aprender prazeroso e instigando-as à construção do pensamento lógico-matemático.
Os dados do estudo corroboram conclusões de pesquisas sobre a formação matemática do professor, como enfatizaram Curi e Pires (2008, p. 181):

[...] tempo insuficiente, levando-se em conta o que outros estudos revelam: a falta de conhecimentos matemáticos dos professores que atuam nessa etapa inicial da escolaridade; no que se refere às discussões sobre questões de natureza didática e metodológica, a abordagem é bastante simplificada, sem o apoio de fundamentações teóricas nem de resultados de pesquisa na área de educação matemática.

Nacarato, Mengali e Passos (2009) afirmam que os níveis de formação dos professores polivalentes demonstram situação desfavorável quando se trata da Matemática, pois os cursos de Pedagogia não se atentam para estas questões. Muitas vezes o professor que fica responsável por essa matéria não está totalmente apto a ela, o que acaba fortalecendo práticas formativas essencialmente no campo do conhecimento pedagógico sem associação com os conceitos fundamentais da disciplina.

O formador responsável pela disciplina de fundamentos do ensino de Matemática precisa abordar, além dos aspectos didáticos, os conteúdos que serão abordados nos primeiros anos de escolarização, uma vez que "[...] os conhecimentos específicos precisam estar articulados à futura prática dessas professoras que irão ensinar matemática [...]" (NACARATO; MENGALI; PASSOS, 2009, p. 36).

Sendo assim, mesmo que a disciplina seja bem fundamentada ainda haverá defasagem e fragilidade da organização curricular o que acaba contribuindo para as dificuldades pedagógicas no início da docência.

\section{CONSIDERAÇÕES FINAIS}

No decorrer do trabalho discorremos sobre algumas das características e problemas da formação para o ensino de Matemática presente no curso de licenciatura em Pedagogia.

A experiência e análise da ementa da disciplina de fundamentos para o ensino dos conteúdos matemáticos possibilitou verificar que para as professoras o ensino da Matemática 
parece ser difícil pelo fato de não terem visto os conteúdos específicos ao longo da formação inicial, pois como podemos constatar a abordagem conceitual ainda é um grande problema tanto para quem vai ensinar quanto para quem vai aprender, pois muitas vezes 0 professor que ministra a disciplina na formação de professores não possui uma trajetória acadêmico-profissional ligada à Educação Matemática.

Além disso, evidencia-se uma formação centrada em procedimentos metodológicos, apresentação de recursos ligados ao jogo sem uma reflexão do ensino e aprendizagem dos conteúdos matemáticos como objeto da formação docente.

O contato com a ementa da disciplina possibilitou-nos a compreensão de que essa se restringe mais aos procedimentos metodológicos e pouco aborda os conteúdos que o professor terá de ensinar, o que, sem dúvidas, reflete no perfil do profissional que ingressa na carreira.

Assim, os achados desse trabalho de campo, quando do momento da escrita deste texto, apontaram que, à primeira vista, as professoras egressas da licenciatura em Pedagogia não estão, na fase de entrada na carreira, preparadas para ensinar conteúdos matemáticos, uma vez que o conhecimento de conteúdo presente na formação inicial não oportuniza condições necessárias para uma efetiva prática pedagógica nesta área de ensino.

\section{REFERÊNCIAS}

BRASIL. Ministério da Educação. Secretaria de Educação Fundamental. Parâmetros Curriculares Nacionais: Matemática (1으 e 2 ciclos do ensino fundamental). Brasília: MEC, 1997. v. 3.

CERQUETTI-ABERKANE, F.; BERDONNEAU, C. O ensino da matemática na educação infantil. Porto Alegre: Artes Médicas, 2001.

CIRÍACO, K. T.; TEIXEIRA, L. R. M. Elementos constitutivos da prática pedagógica nas aulas de Matemática: os saberes adquiridos nos cursos de formação inicial em pedagogia. RPEM, Campo Mourão, v.3, n.5, jul.-dez. 2014.

CURI, E. Formação de professores polivalentes: uma análise de conhecimentos para ensinar Matemática e de crenças e atitudes que interferem na constituição desses conhecimentos. 2004. Tese (Doutorado em Educação Matemática) - Pontifícia Universidade Católica de São Paulo.
CURI, E.; PIRES. C.M.C. Pesquisas sobre a formação de professor que ensina matemática por grupos de pesquisa de instituições paulistanas. Educ. Mat. Pesqui., São Paulo, v.10, n.1, p.151-189, 2008.

DANTE, L. R. Didática da resolução de problemas de matemática: 1a a 5a séries. 12. ed. São Paulo: Ática, 2000.

GOMES, M. G. Obstáculo epistemológicos, obstáculos didáticos e o conhecimento Matemático nos cursos de formação de Professores das séries iniciais no Ensino Fundamental. Contrapontos, ano 2, n.6, p.423437, set./dez. 2002.

KAMII, C. A criança e o número. Campinas: Papirus, 1984.

LÜDKE, M.; ANDRÉ, M. E. D. A. Pesquisa em educação: abordagens qualitativas. São Paulo: EPU, 1986

NACARATO, A. M.; LOPES, C. A. E. (Orgs.). Escritas e leituras na educação matemática. Belo Hotizonte: Autência, 2005.

NACARATO, A. M.; MENGALI, B. L. S.; PASSOS, C. L. B. A matemática nos anos iniciais do ensino fundamental: tecendo fios do ensino e do aprender. Belo Horizonte: Autêntica, 2009.

NARACATO, A. M.; PASSOS, C. L. B.; CARVALHO, D. L. Os graduandos em pedagogia e suas filosofias pessoais frente à matemática e seu ensino. Zetetiké, Campinas, v.12, n.21, jan./jun. 2004.

PANIZZA, M. Ensinar matemática na educação infantil e nas séries iniciais: análise e propostas. Porto Alegre: Artmed, 2006.

PAVANELLO, R. Formação de professores e dificuldades de aprendizagem em Matemática. In: MACIEL, L. S. B.; PAVANELLO, R.; MORAES, S. P. G. (Orgs.). Formação de professores e prática pedagógica. Maringá: Eduem, 2002.

ROCHA, G. A. $O$ início da carreira docente e a formação inicial: problematizando esta relação. $2004 . \quad$ Disponível em <http://27reuniao.anped.org.br/gt08/p083.pdf>. Acesso em: 30 out. 2014.

SMOLE, K. C. S. A matemática na educação infantil: a teoria das inteligências múltiplas na prática escolas. Porto Alegre: Artmed, 2003.

SILVA, L. R. C. et al. Pesquisa documental: alternativa investigativa na formação docente. In: CONGRESSO NACIONAL DE EDUCAÇÃO EDUCERE, 9. ENCONTRO SUL BRASILEIRO DE PSICOPEDAGOGIA, 3. Anais... 2009. Disponível em:

$<$ http://www.pucpr.br/eventos/educere/educere 
2009/anais/pdf/3124_1712.pdf>. Acesso em: 28 jun. 2015.

SOUZA, D. B. Os dilemas do professor iniciante: reflexões sobre os cursos de formação. Revista Multidisciplinar da Uniesp. Saber Acadêmico, n.08, dez. 2009.

VASCONCELLOS, M. O. F. Formação docente e entrada na carreira: uma análise dos saberes mobilizados pelos professores que ensinam matemática nos anos iniciais. 2009. Tese (Doutorado em Educação) - Universidade Federal de Mato Grosso do Sul, Centro de Ciências Humanas e Sociais. Campo Grande - MS.

VEENMAN, S. Problemas percebidos de professores iniciantes. Review of educatinal Research, v. 54, n.2, 1984.

Recebido para publicação em 12/10/2015

Revisado em 07/03/2016

Aceito em 07/06/2016 